\section{Self-Diffusion in Liquid Indium *}

\author{
M. HsieH and R. A. Swalin
}

Department of Chemical Engineering and Materials Science University of Minnesota, Minneapolis, Minnesota 55455

(Z. Naturforsch. 26 a, 328 [1971] ; received 23 December 1970)

Self-diffusion in liquid indium has been studied by CARERI et al. ${ }^{1}$ and by LoDding ${ }^{2}$. There is some disagreement in the results and in addition CARERI et al. reported evidence for a wall effect. Diffusion coefficients calculated for samples held in capillaries of $0.83 \mathrm{~mm}$ I. D. were considerably lower than those calculated for samples held in $1.60 \mathrm{~mm}$ capillaries. These data are shown in Fig. 1. In the course of studies underway in our laboratory, it became necessary to know accurately the self-diffusivity in liquid indium. Consequently an investigation over a limited temperature range was undertaken by use of techniques different from those employed in Ref. 1 and 2. The method used was analogous to the standard "thin layer" slicing method in the solid state. Following LARSSON and LODDING's technique ${ }^{3}$ of preparing samples, a small amount of radioactive indium $-114 \mathrm{~m}$ was placed in the bottom of a $7 \mathrm{~cm}$ long precision bore capillary tube. This tube was made of fused quartz and had an I. D. of one $\mathrm{mm}$. The rest of the capillary was filled with inactive indium metal under vacuum.

A sample thus prepared was held at constant temperature in a silicone oil bath which was stirred continuously. By this technique the temperature variation was kept to less than one degree Celsius.

After diffusion annealing, the capillaries were cut into small sections which were about $5 \mathrm{~mm}$ in length. Each section was carefully weighed and the activity was determined by standard radioactive tracer counting methods.

The small amount of radioactive tracer used as thin "film" weighed about $0.5 \mathrm{mg}$ and was equivalent to a one $\mathrm{mm}$ long radioactive liquid cylinder at end of the $7 \mathrm{~cm}$ long column. For comparison, this would correspond to a surface layer of about one $\mu \mathrm{m}$ in thickness

Reprints request to Prof. Dr. R. A. Swalin, Office of the Dean Institute of Technology University of Minnesota, Minneapolis, Minnesota 55455, USA.

* This research was supported by the U.S. Atomic Energy Commission. on a solid cylinder if a diffusion penetration of about one mm were obtained. From the "thin film" solution of Fick's second law of diffusion ${ }^{4}$ the activity I along the capillary varies according to the following equation.

$$
I=\text { const } \frac{1}{\sqrt{D t}} \exp \left(-\frac{x^{2}}{4 D t}\right)
$$

where $x$ is the distance along the cylinder axis from the closed end and $t$ is the diffusion annealing time.

The diffusion coefficient $D$ was calculated by measurement of the slope on a plot of $\ln I$ versus $x^{2}$. The diffusion coefficients obtained in this investigation are shown in Fig. 1.

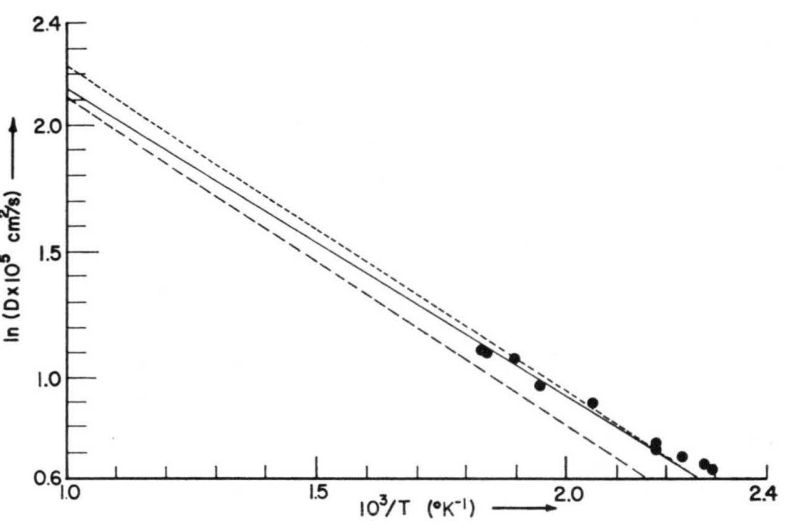

Fig. 1. Self-diffusion in liquid indium as a function of temperature -- - - $1.60 \mathrm{~mm}$. I. D. capillaries, Ref. ${ }^{1}$; $----0.83 \mathrm{~mm}$. I. D. capillaries, Ref. ${ }^{1}$ — Ref. $^{2}$; present data.

It is observed that the data lie closely along the line determined by LoDDING and show no evidence of the wall effect reported by CARERI et al. Thus the results of this investigation which were obtained by a technique different from those employed previously for indium tend to support Lodding's diffusivity data and not those of CARERI et al.

1 G. Careri, A. Paoletti, and M. Vicentini, Nuovo Cim. 10, 1088 [1958].

2 A. Lodding, Z. Naturforsch. 11 a, 200 [1956].

3 S. Larsson and A. Lodding, Private Communication.

4 P. G. Shewmon, Diffusion in Solids, McGraw-Hill Book Co., New York 1963. 